\title{
Explaining trends in Scottish coronary heart disease mortality between 2000 and 2010 using IMPACT SEC model: retrospective analysis using routine data
}

\author{
(9) (1) $\Theta$ OPEN ACCESS
}

Joel W Hotchkiss university veterinary clinician ${ }^{1}$, Carolyn A Davies investigator scientist ${ }^{2}$, Ruth Dundas senior investigator scientist ${ }^{2}$, Nathaniel Hawkins transplant fellow ${ }^{3}$, Pardeep S Jhund clinical lecturer in cardiology ${ }^{4}$, Shaun Scholes research associate ${ }^{5}$, Madhavi Bajekal senior research fellow (honorary) ${ }^{6}$, Martin O'Flaherty senior lecturer in epidemiology ${ }^{7}$, Julia Critchley professor of epidemiology ${ }^{8}$, Alastair H Leyland associate director/programme leader ${ }^{2}$, Simon Capewell professor of clinical epidemiology ${ }^{7}$

\begin{abstract}
${ }^{1}$ School of Veterinary Medicine, University of Glasgow, Glasgow G61 1QH, UK; ${ }^{2} \mathrm{MRC} / \mathrm{CSO}$ Social and Public Health Sciences Unit, University of Glasgow, Glasgow G12 8RZ, UK; ${ }^{3}$ Division of Cardiology, University of British Columbia, Vancouver, BC, Canada V5Z 1M9; ${ }^{4}$ Institute of Cardiovascular and Medical Sciences, University of Glasgow, Glasgow G12 8TA, UK; ${ }^{5} \mathrm{Health}$ and Social Surveys Research Group, University College London, London WC1E 6BT, UK; ${ }^{6}$ Department of Applied Health Research, University College London, London WC1E 7HB, UK; ${ }^{7}$ Department of Public Health and Policy, IPHS, University of Liverpool, Liverpool L69 3GL, UK; ${ }^{8}$ Population Health Research Centre, St George's University of London, London SW17 ORE, UK
\end{abstract}

\begin{abstract}
Objective To quantify the contributions of prevention and treatment to the trends in mortality due to coronary heart disease in Scotland.

Design Retrospective analysis using IMPACT ${ }_{\mathrm{SEC}}$, a previously validated policy model, to apportion the recent decline in coronary heart disease mortality to changes in major cardiovascular risk factors and to increases in more than 40 treatments in nine non-overlapping groups of patients. Setting Scotland.

Participants All adults aged 25 years or over, stratified by sex, age group, and fifths of Scottish Index of Multiple Deprivation.

Main outcome measure Deaths prevented or postponed.

Results 5770 fewer deaths from coronary heart disease occurred in 2010 than would be expected if the 2000 mortality rates had persisted (8042 rather than 13 813). This reflected a $43 \%$ fall in coronary heart disease mortality rates (from 262 to 148 deaths per 100000 ). Improved treatments accounted for approximately $43 \%$ (95\% confidence interval $33 \%$ to $61 \%$ ) of the fall in mortality, and this benefit was evenly distributed across deprivation fifths. Notable treatment contributions came from primary prevention for hypercholesterolaemia (13\%), secondary prevention drugs (11\%), and chronic angina treatments (7\%). Risk factor
\end{abstract}

improvements accounted for approximately $39 \%$ (28\% to $49 \%$ ) of the fall in mortality ( $44 \%$ in the most deprived fifth compared with only $36 \%$ in the most affluent fifth). Reductions in systolic blood pressure contributed more than one third $(37 \%)$ of the decline in mortality, with no socioeconomic patterning. Smaller contributions came from falls in total cholesterol (9\%), smoking (4\%), and inactivity (2\%). However, increases in obesity and diabetes offset some of these benefits, potentially increasing mortality by $4 \%$ and $8 \%$ respectively. Diabetes showed strong socioeconomic patterning (12\% increase in the most deprived fifth compared with $5 \%$ for the most affluent fifth).

Conclusions Increases in medical treatments accounted for almost half of the large recent decline in mortality due to coronary heart disease in Scotland. Furthermore, the Scottish National Health Service seems to have delivered these benefits equitably. However, the substantial contributions from population falls in blood pressure and other risk factors were diminished by adverse trends in obesity and diabetes. Additional population-wide interventions are urgently needed to reduce coronary heart disease mortality and inequalities in future decades. 


\section{Introduction}

Coronary heart disease (CHD) remains the largest cause of death in Scotland, as elsewhere in Europe, the United States, and Australasia. Scotland has one of the highest CHD mortality rates in western Europe, accounting for more than 8000 deaths in 2009. Furthermore, CHD is a major cause of premature mortality (aged $<75$ years). The burden of disease is substantial, and the estimated annual cost to the National Health Service (NHS) in Scotland exceeds £3bn ( $€ 3.7 \mathrm{bn} ; \$ 5 \mathrm{bn}) .{ }^{1} \mathrm{CHD}$ rates have fallen dramatically since the 1970s; age adjusted mortality rates for men dropped from 460 per 100000 in 1979 to 136 per 100000 in 2010, and rates for women dropped from 208 to 64 per $100000 .^{2}$ Studies in the United Kingdom, Europe, United States, and New Zealand have suggested that $45-75 \%$ of the substantial falls in deaths from CHD can be attributed to population-wide decreases in major risk factors such as smoking, blood pressure, and cholesterol..$^{3-7}$ The remaining $25-55 \%$ can apparently be explained by use of cardiological treatments such as thrombolysis, aspirin, angiotensin converting enzyme inhibitors, statins, and coronary artery bypass graft surgery. ${ }^{8}$

In Scotland, and elsewhere, evidence shows strong and persistent socioeconomic inequalities in CHD incidence and mortality. ${ }^{9}{ }^{10}$ O'Flaherty et al reported that premature mortality was up to five times higher in the most deprived fifth compared with the most affluent. Worryingly, mortality trends in younger men and women seemed to have flattened recently, particularly in the two most deprived fifths. ${ }^{9}$ The IMPACT model has been developed to help to explain the decline in CHD deaths by quantifying the contributions of temporal changes in exposure to risk factors and uptake of treatments. ${ }^{11}$ The model has been previously validated and used to explain such falls in mortality in more than 20 countries including Scotland, New Zealand, Finland, England, and the United States. ${ }^{3-7}$ Since 2009, the model has been further developed as IMPACT $\mathrm{SEC}_{\mathrm{S}}$. This permits quantification of trends in CHD mortality, treatment uptakes, and risk factors in socioeconomic fifths. ${ }^{12}$

Recent socioeconomic trends in many cardiovascular risk factors in Scotland have been unfavourable. For example, between 1995 and 2008 relative inequalities in blood pressure levels persisted while inequalities in the prevalence of smoking and diabetes increased in both men and women. ${ }^{13}$ What effect such trends have had on socioeconomic trends in CHD mortality is unclear.

Against this background, we aimed to quantify the decline in CHD mortality between 2000 and 2010 in Scotland and then use the IMPACT $\mathrm{IEC}_{\mathrm{SEC}}$ model to apportion this mortality decline to treatments and changes in risk factors across socioeconomic fifths.

\section{Methods}

\section{IMPACT $_{\text {SEC }}$ model}

The IMPACT CHD mortality model is an epidemiological model originally developed to explore the contribution of modern cardiovascular treatment and changes in risk factors to the decline in CHD mortality in Scotland between 1975 and 1994. ${ }^{34}$ This deterministic, cell based model integrates data from many sources on patient numbers, treatment uptake, treatment effectiveness, risk factor trends, and consequent mortality effects. Using this information, the deaths prevented or postponed between two specified time points can be calculated. The proportion of the decline in CHD mortality over a certain time period can then be attributed to changes in risk factors and to specific treatments.
The model considers a comprehensive range of risk factors, CHD categories, and treatments. In brief, the model includes the population risk factors smoking, cholesterol, blood pressure, obesity, diabetes, and physical activity. It also includes nine mutually exclusive groups of patients: ST elevation myocardial infarction, non-ST elevation acute coronary syndrome, secondary prevention after myocardial infarction, secondary prevention after revascularisation, chronic stable coronary artery disease, patients with severe heart failure requiring at least one admission to hospital, heart failure patients treated only in the community, and two primary pharmacological prevention groups of patients receiving antihypertensive drugs or statins.

The model has been further developed to partition into fifths the socioeconomic components concealed within the overall decline in CHD mortality and within the specific contributions of improved treatments and changes in population risk factors. The IMPACT $\mathrm{SEC}_{\mathrm{SEC}}$ model can be used to synthesise data by fifths of area deprivation from a range of databases (including population, mortality, case fatality, health surveys, hospital admissions, hospital prescribing, and community prescribing). The flexibility of the IMPACT $\mathrm{SEC}_{\mathrm{SC}}$ model also allowed stratification of results by sex; however, we did no formal tests to explore possible disparities by sex. Further details for the IMPACT and the IMPACT $\mathrm{SEC}_{\mathrm{SEC}}$ models are described below and in the summary appendix and technical appendix, as well as in previous publications. ${ }^{11} 12$

\section{Data sources}

We sourced data relating to the Scottish population. We investigated all possible sources and selected the most up to date and representative dataset. Population estimates and CHD death counts (ICD10 (international classification of diseases, 10th revision) codes I10-I25) for 2000 and for 2010 by 10 year age bands (25-34 to $\geq 85$ years), sex, and deprivation fifth came from National Records of Scotland (www.nrscotland.gov.uk/). Emergency admissions and surgical interventions for acute myocardial infarction and unstable angina, as well as admissions for heart failure, came from the linked Scottish Morbidity Record (SMR01) and death record dataset provided by Information Services Division Scotland (www.isdscotland.org/ ). Primary Care Clinical Informatics Unit, University of Aberdeen (www.abdn.ac.uk/pcciu/index.htm), provided information on treatment uptake in community based patients. Data on trends in risk factors came from the Scottish Health Surveys. ${ }^{14} 1516{ }^{17}$ Rehabilitation data came from Information Services Division Scotland. Treatment uptake data for heart failure in hospital came from the Healthcare Improvement Scotland audit (www.healthcareimprovementscotland.org). We substituted English data from the Myocardial Ischaemia National Audit Project (MINAP) for uptake of acute coronary syndrome treatment in hospital. ${ }^{12}$ HeartStart (Scotland) provided community cardiopulmonary resuscitation data for ST elevation myocardial infarction patients. ${ }^{18}$

\section{Socioeconomic deprivation}

We used the Scottish Index of Multiple Deprivation 2009v2 as a measure of area level deprivation. ${ }^{19}$ This identifies small concentrations of deprivation across Scotland by using data from various sources from around 2007-08. It is based on the stable and consistent small area geography called data zones, of which there are 6505 in Scotland (average population 798 (range 0-7061) people) ranked from most deprived (1) to least deprived (6505). The overall rankings are made up of seven individual domains: current income, employment, health, education, housing, access to services, and crime. On the basis 
of their postcode of residence, the data providers allocated patients treated in hospital or in the community to the corresponding deprivation fifth (to protect patients' anonymity). Survey respondents and deaths were matched to deprivation fifths in a similar manner. We could not obtain data from the Primary Care Clinical Informatics Unit stratified by people's Scottish Index of Multiple Deprivation area of residence. We therefore substituted this by using the 2001 Carstairs index of deprivation applied to the area of residence..$^{20}$ This applied to patient numbers for chronic angina and heart failure in the community, as well as uptake of therapeutic drugs for all the community groups. We used a $\chi^{2}$ test for linear trend across deprivation fifths to assess socioeconomic gradients associated with the proportion of CHD deaths explained by the model.

\section{Deaths prevented or postponed}

We calculated the number of CHD deaths expected in 2010 by indirect standardisation, multiplying the age, sex, and Scottish Index of Multiple Deprivation fifth specific mortality rates from CHD in 2000 by the relevant population counts for 2010 .

Summing over all strata then yielded the expected number of deaths. The difference between the number of expected and observed deaths then represented the fall in mortality, the total number of CHD deaths prevented or postponed to be explained by the combined changes in risk factor levels and treatment uptake between 2000 and 2010. If the model did not fully explain all deaths prevented or postponed in each fifth, we assumed any shortfalls to reflect unmeasured risk factors or imprecision in the model's parameters.

\section{Mortality reductions attributable to treatment uptake}

We specified relevant treatments for each of the nine mutually exclusive patient groups. These included acute myocardial infarction (cardiopulmonary resuscitation, thrombolysis, angioplasty, aspirin, $\beta$ blockers, and angiotensin converting enzyme inhibitors); secondary prevention following acute myocardial infarction and, separately, following coronary artery bypass graft surgery or angioplasty (aspirin, $\beta$ blockers, angiotensin converting enzyme inhibitors, statins, warfarin, and rehabilitation); non-ST elevation myocardial infarction/acute coronary syndrome (aspirin, heparin, platelet glycoprotein IIB/IIIA inhibitors, and clopidogrel); chronic angina (coronary artery bypass graft surgery, angioplasty, aspirin, statins); and heart failure (angiotensin converting enzyme inhibitors, $\beta$ blockers, spironolactone, aspirin, statins).

To avoid double counting of patients, we used linked individual data where possible; where this was not possible, we constructed distinct, non-overlapping CHD patient subgroups (see technical appendix). Numbers of patients eligible for each treatment, uptake of treatment, one year case fatality rates, and relative risk reduction due to treatment (all stratified by age, sex, patient subgroup, and deprivation fifth) came from relevant data sources as specified. As all treatments were in use in 2000 , we calculated the net benefit of medical intervention in 2010 by subtracting the expected number of deaths prevented if the uptake rates in 2000 remained constant from the estimated number of deaths prevented calculated using the 2010 uptake rates (see technical appendix).

\section{Mortality reductions attributable to risk factor changes}

We included six major cardiovascular risk factors in the model: the behavioural markers of smoking, physical inactivity, and body mass index and the physiological markers of systolic blood pressure, total serum cholesterol, and diagnosed diabetes. We calculated the absolute change in each risk factor between 2000 and 2010 by using generalised linear models with normal distribution and identity link for the continuous risk factors and generalised linear models with a binomial distribution and a logit link function for categorical variables (technical appendix, table C).

We estimated the mortality benefits of an absolute change in each risk factor between 2000 and 2010 by using a regression based approach for factors measured on a continuous scale (such as total blood cholesterol), using sex and age specific independent regression coefficients of mortality benefit for a unit change in mean risk factor obtained from published multivariate analyses (technical appendix, table I). For binary variables (such as smoking), we used a population attributable risk fraction approach using sex and age specific relative risks from the most recent meta-analyses and population cohort studies (technical appendix, table J). We jointly estimated mortality benefits of changes in risk factors by using the cumulative risk reduction approach, rather than simple addition (technical appendix, section 1.3).

We assumed that no further synergy existed between the treatment and risk factor components of the model. We assumed lag times between the change in cardiovascular risk factor levels and change in CHD mortality rates to be relatively rapid, ${ }^{21}$ so we did not specifically model them.

\section{Uncertainty analysis}

We calculated $95 \%$ uncertainty intervals around the model output (that is, deaths prevented or postponed ) by using Monte Carlo simulation, much as in health economic evaluation studies. ${ }^{22}$ This calculation involved replacing all fixed input parameters used in the model by appropriate probability distributions and repeatedly recalculating the model output with values sampled from the defined input distributions. We used the Excel add-in Ersatz software (www.epigear.com) to do 1000 runs to determine the $95 \%$ uncertainty intervals of the deaths prevented or postponed (2.5th and 97.5 th centile values corresponding to the lower and upper limits) (see technical appendix).

\section{Results}

The age standardised CHD mortality rate in adults aged 25 years and over fell by $43 \%$ between 2000 and 2010, from 262 to 148 deaths per 100000 population (table $1 \Downarrow$ ). Mortality rates in 2000 in the most affluent fifth were 181 per 100000 population compared with 349 per 100000 in the most deprived fifth. Furthermore, the pace of fall differed significantly; the most affluent fifth decreased by $5.8 \%$ a year compared with $4.6 \%$ in the most deprived fifth. Thus absolute inequalities narrowed over the 10 year time period, whereas relative inequalities widened.

In total, 5770 fewer CHD deaths occurred in 2010 than would have been expected had the 2000 mortality rates persisted; this figure represents the total deaths prevented or postponed. One thousand two hundred and thirty deaths were prevented or postponed in the most deprived fifth, compared with 905 in the most affluent fifth (reflecting the higher initial burden of disease; table $1 \Downarrow$ ). When examining the deaths prevented or postponed as a percentage of expected deaths (percentage of deaths prevented or postponed), we observed a significant inequality gradient with a decrease in mortality of $44 \%$ in the most affluent 
fifth and $38 \%$ in the most deprived fifth; this gradient was also evident with stratification by sex.

As a result of improvements in the uptake of medical and surgical treatments, 2480 fewer deaths occurred. This accounted for $43 \%$ (95\% confidence interval $33 \%$ to $61 \%$ ) of the fall in total CHD mortality in Scotland (table $2 \Downarrow$ ); minimal difference existed in this proportion by sex (table $3 \Downarrow$ ). No significant socioeconomic gradient existed (46\% in the most affluent fifth and $44 \%$ in the most deprived fifth), and this was true for each sex (table $3 \Downarrow$ ). Population level changes in risk factors accounted for approximately 2240 fewer deaths or $39 \%$ (29\% to $49 \%$ ) of the fall (table $4 \Downarrow$ ). These accounted for $36 \%$ of the deaths prevented or postponed in the most affluent fifth, increasing to $44 \%$ in the most deprived fifth. Again, minimal difference existed in these proportions by sex (table $3 \Downarrow$ ). The model could therefore explain only $82 \%$ of the overall fall in mortality (a shortfall of some 1055 deaths) (tables $3 \Downarrow$ and $4 \Downarrow$ ). A socioeconomic gradient was evident; $81 \%$ of deaths prevented or postponed were explained in the most affluent fifth and $88 \%$ in the most deprived fifth.

\section{Increased treatments}

The largest contribution to deaths prevented by increased uptake of treatment came from statin treatment for hyperlipidaemia (approximately 13\% of the total mortality reduction), followed by secondary prevention after myocardial infarction (9\%) and management of chronic stable coronary artery disease (7\%) (table $2 \Downarrow$ ). Uptake rates of statins and angiotensin converting enzyme inhibitors or angiotensin receptor blockers more than doubled between 2000 and 2010 for secondary prevention and the management of stable coronary artery disease (table $5 \Downarrow$ ). These two treatments together contributed to approximately $750(13 \%)$ deaths prevented or postponed. Improved heart failure treatments contributed approximately $265(5 \%)$ deaths prevented or postponed in community patients and $85(2 \%)$ fewer deaths in patients admitted to hospital. Only small contributions to deaths prevented or postponed were made in the hospital based patient groups of emergency admissions for acute coronary syndromes (table $2 \Downarrow$ ).

The improvements due to changes in treatment uptakes were evenly distributed across deprivation fifths. The difference between the most and least deprived fifths in terms of percentage of deaths prevented or postponed was generally less than $1 \%$ for each treatment group (table $3 \Downarrow$ ).

\section{Risk factor changes}

The largest contribution from population level changes in risk factors came from the $2 \mathrm{~mm} \mathrm{Hg}$ fall in systolic blood pressure in people not on antihypertensive drugs; this generated approximately 2130 fewer deaths, representing $37 \%$ of the mortality decrease (table $4 \Downarrow$ ). In contrast, the benefits from treatment of hypertension were fairly small, with some 155 (3\%) deaths averted (table $2 \Downarrow$ ). Socioeconomic gradients were modest; however, population level systolic blood pressure dropped during the 10 year period by $3.2 \mathrm{~mm} \mathrm{Hg}$ in women and by only $0.9 \mathrm{~mm} \mathrm{Hg}$ in men (table $6 \Downarrow$ ).

The fall in cholesterol concentrations in the population not on statin treatment accounted for approximately 510 deaths averted, representing $9 \%$ of the total fall. In both absolute and relative terms, the fall in deaths attributable to cholesterol reduction in the general population was substantially higher in the most deprived fifth $(170(14 \%)$ fewer deaths) than in the most affluent fifth (43 (5\%) fewer deaths). During the 10 year study period, uptake of statin treatment increased substantially, from $3 \%$ of eligible people in 2000 to $15 \%$ in 2010 (13\% in the most affluent fifth and $17 \%$ in the most deprived fifth) (table $5 \Downarrow$ ). Cholesterol lowering by statins thus accounted for approximately $770(13 \%)$ deaths averted, $15 \%$ in the most affluent fifth and $11 \%$ in the most deprived fifth (table $2 \Downarrow$ ).

Favourable trends in the behavioural risk factors made a modest contribution to deaths prevented or postponed; the drop in smoking rates contributed to approximately 210 fewer deaths or $4 \%$ (table $4 \Downarrow$ ). Smoking prevalence dropped by about $4 \%$ in men and $5 \%$ in women over the 10 year time period. A significant socioeconomic gradient was apparent, with approximately $14(2 \%)$ fewer deaths evident in the most affluent fifth and some $75(6 \%)$ fewer deaths in the most deprived fifth (table $3 \Downarrow$ ), reflecting larger declines in smoking prevalence. Physical inactivity declined by approximately $7 \%$ in men and $6 \%$ in women (table $6 \Downarrow$ ) and contributed to approximately 100 (2\%) fewer deaths.

\section{Adverse risk factor trends}

The mortality gains from decreases in smoking and physical inactivity were cancelled out by increases in obesity and diabetes. Increases in body mass index contributed approximately $235(-4 \%)$ additional deaths and diabetes some $475(-8 \%)$ additional deaths (table $4 \Downarrow$ ). The additional deaths from diabetes showed a significant socioeconomic gradient, with $48(-5 \%)$ more deaths in the most affluent fifth and 141 $(-12 \%)$ in the most deprived fifth (table $3 \Downarrow)$. This reflected a gradient in prevalence of diabetes which increased in men by $2 \%$ (1\% in women) in the most affluent fifth and by $4 \%$ (3\% in women) in the most deprived fifth (table $6 \Downarrow$ ). No significant socioeconomic gradients were associated with body mass index attributable deaths (tables $3 \Downarrow$ and $4 \Downarrow$ ).

\section{Discussion}

Coronary heart disease remains a top policy priority in Scotland. CHD mortality fell by more than $40 \%$ between 2000 and 2010 , resulting in approximately 5770 fewer deaths. The largest contributors to this decline were favourable population level falls in blood pressure and serum cholesterol concentrations. However, we found evidence of unfavourable trends in body mass index and diabetes that threaten to reverse these trends. The falls in mortality were steeper in the more affluent groups, so relative inequalities remained fairly constant. These differentials are likely to reflect inequalities in risk factor trends, rather than in evidence based treatments (which were remarkably equitable).

Reductions in cardiovascular risk factor levels explained approximately two fifths of the fall in CHD mortality. The single largest contribution came from secular falls in population blood pressure. Furthermore, blood pressure falls were of a similar magnitude across socioeconomic groups. This is consistent with the encouraging population-wide reductions in dietary salt consumption seen in Scotland and England. ${ }^{1323}$ The greater fall in blood pressure in women than in men resulted in a correspondingly larger contribution to the CHD deaths prevented. The underlying contributory factors therefore represent a possible area for future investigation. As elsewhere, the mortality benefit from hypertension treatments was relatively small.

Favourable trends in smoking and physical activity made only a modest contribution to the falls in mortality. However, the reductions in deaths due to smoking were greater in the deprived groups, mirroring the larger declines in smoking prevalence. This may reflect the benefits of smoke-free legislation 
introduced in Scotland in 2006. ${ }^{24}$ However, smoking remains prevalent in deprived areas and substantial inequalities persist, representing a government policy priority. ${ }^{25} 26$

Modest mortality benefits were also attributable to population declines in cholesterol concentrations in people not on statin treatment, again greater in deprived groups. These benefits may reflect modest decreases in dietary saturated fat consumption and increases in fruit and vegetable consumption. However, the small benefits were notably less than for statin treatment. Furthermore, the Scottish government's dietary targets were not met, ${ }^{27}$ leaving little room for complacency.

\section{Adverse trends}

Falls in major cardiovascular risk factor levels explained approximately $40 \%$ of the fall in CHD mortality. However, the net benefit was substantially reduced by increasing levels of obesity and diabetes, which together increased mortality by $12 \%$ (>700 additional deaths). Increasing prevalence of diabetes showed a strong socioeconomic gradient whereby surplus deaths were almost three times higher in the most deprived group than the most affluent. This represents a clarion call to policy makers. ${ }^{28}$

\section{Treatment contributions}

Approximately $40 \%$ of the total fall in CHD mortality was attributable to improvements in the uptake of treatments, notably a doubling in drug use in the community. Medical interventions in hospital settings made only a small additional contribution because CHD incidence rates are declining with fewer patients therefore being admitted to hospital with acute disease, treatment uptakes were already high (hence with little margin for further increases), and few new treatments were introduced during the study period.

Although the CHD disease burden showed strong socioeconomic gradients, the improvements in mortality due to changes in treatment uptake were fairly evenly distributed across deprivation fifths. This is gratifying and suggests an equitable delivery of CHD care by the Scottish NHS. Subjectively, sex equality also existed in the delivery of care, although this requires further formal investigation.

\section{Comparison with England IMPACT SEC $_{\text {model }}$}

Our analysis is only the second IMPACT $\mathrm{IEC}_{\mathrm{SE}}$ study to examine socioeconomic trends in CHD mortality. It thus begs comparison with the first, which modelled similar English data between 2000 and $2007 .^{12}$

As expected, many similarities exist, including substantial and persistent socioeconomic inequalities in CHD death rates and smoking levels. Overall mortality falls were equally large, and in both cases a third was attributable to changes in risk factors. The biggest contribution to the fall in mortality was consistently attributed to declines in population blood pressure (37\% in Scotland and 30\% in England), partly reflecting reductions in dietary salt. In both countries, worrying adverse trends in body mass index and diabetes equated to substantial rises in coronary mortality (12\% in Scotland; 9\% in England).

The Scottish model attributed approximately $40 \%$ of the total fall in CHD mortality to improved uptakes of medical treatments, compared with 50\% in England. Importantly, both models showed equitable reductions in mortality attributable to treatments across socioeconomic groups, most likely reflecting the uniform health service provision for CHD treatments.

\section{Strengths and limitations}

This is the first study to use local datasets to quantify detailed contributions of changes in treatment and risk factors to falls in coronary mortality within socioeconomic groups in Scotland. It is only the second IMPACT study to examine socioeconomic variations. Scotland benefits from having the only UK morbidity databases that routinely link all hospital admission information with all mortality data. This should generate accurate estimates of various patient groups, incidence, and case fatality stratified by age, sex, and, where numbers are large enough, deprivation. This minimised the assumptions that had to be made regarding overlap between disease groups by ensuring that people could be included in only one group. Some data were difficult to access, perhaps reflecting insufficient resources to sustain diverse audit projects.

Several limitations should also be acknowledged. Firstly, the routine data used in this study permitted stratification by an area based measure of deprivation, but not by individual person. However, such small area indices offer reasonably effective markers of personal social status. ${ }^{29}$

Secondly, mortality rates are dependent on population estimates. Because population estimates from the 2011 census were not yet available, the small area population estimates by data zone needed for our Scottish Index of Multiple Deprivation stratified analysis were based on the 2000 census with populations rolled forward to $2010 .^{30}$ Clearly, small areas may change over time with regards to population size, demographic characteristics, and socioeconomic make-up, so estimates of mortality rates may be less stable in 2010 .

Thirdly, our model could not explain $18 \%$ of the overall decline in CHD mortality; uncertainty analyses would suggest that this figure could be as little as $1 \%$ or as much as $35 \%$. Several possible explanations exist for this shortfall. Firstly, risk factor estimates obtained from the Scottish Health Survey may lack precision owing to small numbers, compounded by self reporting of smoking and inactivity levels and declining survey response rates. ${ }^{31}$ Secondly, other risk factors such as psychosocial stress and dietary consumption of fruit and vegetables, saturated fat, or alcohol were omitted from our model. However, the effect of these "upstream" factors should be partly quantified by trends in "downstream" factors (blood pressure, cholesterol, body mass index, and diabetes). ${ }^{32}$ Furthermore, the consistent results from the rigorous sensitivity analyses were reassuring.

\section{Policy implications}

The substantial decline in CHD mortality over the past decade in Scotland can be attributed fairly equally to increased medical treatments and to improvements in risk factors. However, the potentially powerful reductions in smoking and cholesterol were frustratingly small and were completely negated by large adverse trends in obesity and diabetes. Scotland's past tobacco and dietary policies deserve credit. ${ }^{25}{ }^{26}$ However, more effective public health policies exist elsewhere and have substantially and equitably reduced the intake of saturated fats, trans fats, salt, and sugars. ${ }^{28}{ }^{33}{ }^{34}$ Likewise, proposed standard packaging legislation, ${ }^{26}$ if implemented, could lower smoking in all socioeconomic groups and thus reduce CHD mortality across Scotland.

We thank the Scottish Centre for Social Research (ScotCen) for providing the Scottish Health Survey data and for attaching Scottish Index of Multiple Deprivation fifths; in particular, we acknowledge Joan Corbett, Jackie Palmer, Catherine Bromley, and Lisa Rutherford. We also thank Sai Bhagram, Henry Dargie, and Mark Petrie for providing 


\section{What is already known on this topic}

In spite of recent falls in mortality, coronary heart disease (CHD) remains the largest cause of death in Scotland and generates strong and persistent socioeconomic inequalities

Smoking prevalence in Scotland has fallen, but absolute levels remain high

Worryingly, other cardiovascular risk factors such as obesity and diabetes have recently increased

\section{What this study adds}

CHD mortality in Scotland fell by $43 \%$ between 2000 and 2010; the single largest contribution came from population level falls in blood pressure

The contribution from improvements in smoking and cholesterol concentrations was frustratingly small and was completely negated by increases in obesity and diabetes

The CHD burden showed strong socioeconomic gradients; however, the mortality reductions attributable to improved treatment uptakes were evenly distributed across socioeconomic fifths, suggesting an equitable delivery of care by the Scottish NHS

the National Heart Failure Audit data; Jill Pell, Danny Mackay, and Stuart Cobbe for extracting and providing the HeartStart (Scotland) community cardiopulmonary resuscitation data; Colin Simpson for his input in the Primary Care Clinical Informatics Unit application; the Information Services Division of NHS Scotland for providing hospital admission data; and the National Records of Scotland for providing population and mortality data. Martin Denvir and lan Finlay provided invaluable advice regarding hospital treatment data.

Contributors: SC, JWH, and AHL conceived and designed the experiments. JWH extracted data, populated the model, analysed the data, and coordinated the project. CAD wrote the first draft of the manuscript. JWH, SC, RD, NH, PSJ, SS, MB, MO'F, JC, and AHL all contributed to the writing of the manuscript. All authors agreed with the manuscript's results and conclusions. SC and AHL supervised the research. $\mathrm{AHL}$ is the guarantor.

Funding: This research was funded by EUROHEART II (predicting future CVD trends under different policy scenarios in the EU: impact CVD 2020, ADONIS code A/100946) and the Medical Research Council/Chief Scientist Office Social and Public Health Sciences Unit (MRC/CSO SPHSU), University of Glasgow, as part of the "Measuring health, variations in health and determinants of health" programme,

MC_US_A540_0001.

Competing interests: All authors have completed the ICMJE uniform disclosure form at www.icmje.org/coi_disclosure.pdf (available on request from the corresponding author) and declare: $\mathrm{CD}, \mathrm{JH}, \mathrm{SC}$, and $A L$ received a research grant for the submitted work from EUROHEART II; MB and SS reported grants from Legal and General Assurance Society during the conduct of the study; no financial relationships with any other organisations that might have an interest in the submitted work in the previous three years; no other relationships or activities that could appear to have influenced the submitted work.

Ethical approval: This study was based on the analysis of routinely collected mortality, hospital admission, survey, and audit data, all of which were anonymised and as such did not require ethical approval.

Data sharing: The Scottish Health Survey datasets are available from the UK Data Service (formerly the Economic and Social Data Service) Catalogue http://discover.ukdataservice.ac.uk/series/?sn=2000047. Mortality data are available from National Records Scotland, and hospital admission data are available from the Information Services Division; these must be applied for on an individual study basis through the NHS National Services Scotland Privacy Advisory Committee www.nhsnss. org/pages/corporate/privacy_advisory_committee.php.

Transparency declaration: AHL affirms that this manuscript is an honest, accurate, and transparent account of the study being reported; that no important aspects of the study have been omitted; and that any discrepancies from the study as planned have been explained.

1 Scarborough P, Bhatnager P, Wickramasimghe K, Smolina K, Mitchell C, Rayner M. Coronary heart disease statistics. British Heart Foundation, Department of Public Health, University of Oxford, 2013.
2 National Records of Scotland (formerly General Register Office for Scotland). Age-standardised death rates calculated using the European Standard Population. www. gro-scotland.gov.uk/statistics/theme/vital-events/deaths/age-standardised-rates.html.

3 Capewell S, Morrison CE, McMurray JJ. Contribution of modern cardiovascular treatment and risk factor changes to the decline in coronary heart disease mortality in Scotland between 1975 and 1994. Heart 1999;81:380-6.

4 Unal B, Critchley JA, Capewell S. Explaining the decline in coronary heart disease mortality in England and Wales between 1981 and 2000. Circulation 2004;109:1101-7.

5 Laatikainen T, Critchley JA, Vartiainen E, Salomaa V, Ketonen M, Capewell S. Explaining the decline in coronary heart disease mortality in Finland between 1982 and 1997. Am J Epidemiol 2005;162:764-73.

6 Ford ES, Ajani UA, Croft JB, Critchley JA, Labarthe DR, Kottke TE, et al. Explaining the decrease in U.S. deaths from coronary disease, 1980-2000. N Engl J Med 2007;356:2388-98

7 Capewell S, Beaglehole R, Seddon M, McMurray J. Explanation for the decline in coronary heart disease mortality rates in Auckland, New Zealand, between 1982 and 1993. Circulation 2000;102:1511-6.

8 Ford ES, Capewell S. Proportion of the decline in cardiovascular mortality disease due to prevention versus treatment: public health versus clinical care. Annu Rev Public Health 2011:32:5-22.

9 O'Flaherty M, Bishop J, Redpath A, McLaughlin T, Murphy D, Chalmers J, et al. Coronary heart disease mortality among young adults in Scotland in relation to social inequalities: time trend study. BMJ 2009;339:b2613.

10 Davies CA, Dundas R, Leyland AH. Increasing socioeconomic inequalities in first acute myocardial infarction in Scotland, 1990-92 and 2000-02. BMC Public Health 2009-9:134.

11 Unal B, Critchley JA, Capewell S. IMPACT, a validated, comprehensive coronary heart disease model. University of Liverpool, 2007.

12 Bajekal M, Scholes S, Love H, Hawkins NM, O'Flaherty M, Raine R, et al. Analysing recent socioeconomic trends in coronary heart disease mortality in England, 2000-2007: a population modelling study. PLoS Med 2012;9:e1001237.

13 Hotchkiss JW, Davies CA, Gray L, Bromley C, Capewell S, Leyland AH. Trends in adult cardiovascular disease risk factors and their socio-economic patterning in the Scottish population 1995-2008: cross-sectional surveys. BMJ Open 2011;1:e000176.

14 Bromley C, Bradshaw P, Given L, eds. The Scottish health survey 2008. Scottish Government, 2009.

15 Bromley C, Given L, Ormston R, eds. The Scottish health survey 2009. Scottish Government, 2010.

16 Bromley C, Sproston K, Shelton N, eds. The Scottish health survey 2003. Scottish Executive, 2005

17 Shaw A, McMunn A, Field J, eds. The Scottish health survey 1998. Stationery Office, 2000.

18 Cobbe SM, Redmond MJ, Watson JM, Hollingworth J, Carrington DJ. "Heartstart Scotland"-initial experience of a national scheme for out of hospital defibrillation. BMJ 1991:302:1517-20.

19 Scottish Government. Scottish Index of Multiple Deprivation: 2009 general report. Scottish Government, 2009

20 Carstairs VRM. Deprivation and health in Scotland UK. Health Bull (Edinb) 1990;48:162-75.

21 Kuulasmaa K, Tunstall-Pedoe H, Dobson AJ, Fortmann SP, Sans S, Tolonen H, et al. Estimation of contribution of changes in classic risk factors to trends in coronary-event rates across the WHO MONICA Project populations. Lancet 2000;355:675-87.

22 Barendregt JJ. The effect size in uncertainty analysis. Value Health 2010;13:388-91.

23 UK Food Standards Agency. An assessment of dietary sodium levels among aduls (aged 19-64) in the UK general population in 2008, based on analysis of dietary sodium in 24 hour urine samples. National Centre for Social Research, 2008.

24 Scottish Parliament. Smoking, Health and Social Care (Scotland) Act 2005. Scottish Parliament, 2005.

25 ASH Scotland. ASH Scotland strategic plan 2010-2015. ASH Scotland, 2010

26 Scottish Government. Creating a tobacco-free generation: a tobacco control strategy for Scotland. Scottish Government, 2013.

27 Scottish Government. Food and drink in Scotland: key facts 2012. Scottish Government 2012.

28 Mozaffarian D, Capewell S. United Nations' dietary policies to prevent cardiovascular disease. BMJ 2011;343:d5747.

29 Woodward M. Small area statistics as markers for personal social status in the Scottish heart health study. J Epidemiol Community Health 1996;50:570-6.

30 Northern Ireland Statistics and Research Agency (NISRA). Small area population estimates across the UK. NISRA, 2011.

31 Tolonen H, Dobson A, Kulathinal S. Effect on trend estimates of the difference between survey respondents and non-respondents: results from 27 populations in the WHO MONICA project. Eur J Epidemiol 2005;20:887-98.

32 Scottish Intercollegiate Guidelines Network (SIGN). Risk estimation and the prevention of cardiovascular disease: a national clinical guideline. SIGN, 2007.

33 Capewell S, Graham H. Will cardiovascular disease prevention widen health inequalities? PLoS One 2010;7:e1000320. 
34 National Institute for Health and Care (NICE). Prevention of cardiovascular disease: NICE public health guidance 25. NICE, 2010.

Accepted: 17 January 2014

Cite this as: BMJ 2014;348:g1088
This is an Open Access article distributed in accordance with the Creative Commons Attribution Non Commercial (CC BY-NC 3.0) license, which permits others to distribute, remix, adapt, build upon this work non-commercially, and license their derivative works on different terms, provided the original work is properly cited and the use is non-commercial. See: http://creativecommons.org/licenses/by-nc/3.0/. 


\section{Tables}

Table 1| Population, observed coronary heart disease deaths/age standardised rates for 2000 and 2010, and deaths prevented or postponed (DPPs) in Scotland stratified by deprivation fifths; data presented for whole population as well as by sex

\begin{tabular}{|c|c|c|c|c|c|c|}
\hline & \multirow[b]{2}{*}{ Scotland } & \multicolumn{5}{|c|}{ Scottish Index of Multiple Deprivation fifths } \\
\hline & & 1 (most affluent) & 2 & 3 & 4 & 5 (most deprived) \\
\hline \multicolumn{7}{|l|}{ All adults aged $\geq 25$ years } \\
\hline \multicolumn{7}{|l|}{ Population: } \\
\hline 2000 & 3516000 & 685162 & 678440 & 705803 & 726937 & 719658 \\
\hline 2010 & 3685544 & 735789 & 761624 & 755559 & 736790 & 695782 \\
\hline \multicolumn{7}{|l|}{ Observed deaths: } \\
\hline 2000 & 12260 & 1553 & 1965 & 2563 & 2927 & 3252 \\
\hline 2010 & 8042 & 1137 & 1417 & 1579 & 1920 & 1989 \\
\hline \multicolumn{7}{|l|}{ Age standardised rates (per 100000$)^{*}$ : } \\
\hline $2000(95 \% \mathrm{Cl})$ & 262 (257 to 266 ) & 181 (171 to 190$)$ & 215 (206 to 225 ) & 263 (253 to 274 ) & 283 (272 to 293 ) & 349 (337 to 361$)$ \\
\hline $2010(95 \% \mathrm{Cl})$ & 148 (145 to 151$)$ & $100(94$ to 106$)$ & 120 (113 to 126$)$ & 137 (130 to 144$)$ & 177 (168 to 185$)$ & 217 (207 to 227) \\
\hline Annual \% fall & 5.5 & 5.8 & 5.7 & 6.3 & 4.6 & 4.6 \\
\hline $\begin{array}{l}\text { Expected deaths in } 2010 \text { (if } 2000 \text { rates had } \\
\text { persisted) }\end{array}$ & 13813 & 2042 & 2476 & 2971 & 3107 & 3218 \\
\hline $\begin{array}{l}\text { Deaths prevented or postponed } \\
\text { (expected-observed deaths) }\end{array}$ & 5770 & 905 & 1060 & 1390 & 1185 & 1230 \\
\hline DPPs as $\%$ of expected deaths $\dagger$ & 41.8 & 44.3 & 42.8 & 46.9 & 38.2 & 38.2 \\
\hline \multicolumn{7}{|l|}{ Men aged $\geq 25$ years } \\
\hline \multicolumn{7}{|l|}{ Age standardised rates (per 100000$)^{*}:$} \\
\hline $2000(95 \% \mathrm{Cl})$ & 363 (354 to 372 ) & 252 (235 to 270$)$ & 293 (275 to 311$)$ & 364 (344 to 383 ) & 393 (373 to 413$)$ & 494 (471 to 518$)$ \\
\hline $2010(95 \% \mathrm{Cl})$ & 210 (204 to 216$)$ & 139 (128 to 150$)$ & 169 (157 to 181$)$ & 197 (184 to 210$)$ & 253 (238 to 269 ) & 313 (295 to 332$)$ \\
\hline Annual \% fall & 5.3 & 5.8 & 5.4 & 5.9 & 4.3 & 4.5 \\
\hline $\begin{array}{l}\text { Expected deaths in } 2010 \text { (if } 2000 \text { rates had } \\
\text { persisted) }\end{array}$ & 7603 & 1119 & 1348 & 1653 & 1684 & 1799 \\
\hline $\begin{array}{l}\text { Deaths prevented or postponed } \\
\text { (expected-observed deaths) }\end{array}$ & 3075 & 495 & 565 & 745 & 605 & 665 \\
\hline DPPs as $\%$ of expected deathsł & 40.4 & 44.2 & 41.9 & 45.1 & 35.9 & 37.0 \\
\hline \multicolumn{7}{|l|}{ Women aged $\geq 25$ years } \\
\hline \multicolumn{7}{|l|}{ Age standardised rates (per 100000$)^{*}:$} \\
\hline $2000(95 \% \mathrm{Cl})$ & $185(180$ to 190$)$ & 129 (119 to 139$)$ & 155 (145 to 166$)$ & $186(175$ to 197$)$ & 201 (190 to 213 ) & 239 (226 to 252$)$ \\
\hline $2010(95 \% \mathrm{Cl})$ & 99 (96 to 103$)$ & 69 (63 to 76$)$ & 81 (74 to 87$)$ & 91 (83 to 98$)$ & 118 (109 to 127$)$ & $141(131$ to 151$)$ \\
\hline Annual \% fall & 6.0 & 6.0 & 6.3 & 6.9 & 5.2 & 5.1 \\
\hline $\begin{array}{l}\text { Expected deaths in } 2010 \text { (if } 2000 \text { rates had } \\
\text { persisted) }\end{array}$ & 6210 & 923 & 1128 & 1317 & 1423 & 1419 \\
\hline $\begin{array}{l}\text { Deaths prevented or postponed } \\
\text { (expected-observed deaths) }\end{array}$ & 2695 & 410 & 495 & 645 & 580 & 565 \\
\hline DPPs as $\%$ of expected deaths§ & 43.4 & 44.4 & 43.9 & 49.0 & 40.8 & 39.8 \\
\hline
\end{tabular}

DPPs have been rounded to nearest 5 .

${ }^{*}$ Rates are standardised to European standard population aged $\geq 25$ years by using direct standardisation.

$t \mathrm{x}^{2}$ test for linear trend across deprivation fifths $\mathrm{P}<0.0001$.

$\neq \chi^{2}$ test for linear trend across deprivation fifths $P<0.0001$.

$\S \chi^{2}$ test for linear trend across deprivation fifths $\mathrm{P}=0.002$. 
Table 2| Coronary heart disease deaths prevented or postponed (DPPs) owing to changes in treatment uptake between 2000 and 2010 in Scotland, stratified by deprivation fifth

\begin{tabular}{|c|c|c|c|c|c|c|c|}
\hline \multirow[b]{2}{*}{ Treatments by patient groups } & \multirow[b]{2}{*}{ All } & \multirow{2}{*}{$\begin{array}{l}\text { Proportion of total } \\
\text { DPPs-\% }(95 \% \\
\text { uncertainty } \\
\left.\text { interval }{ }^{\star}\right)\end{array}$} & \multicolumn{5}{|c|}{ Scottish Index of Multiple Deprivation fifths } \\
\hline & & & $\begin{array}{l}1 \text { (most } \\
\text { affluent) }\end{array}$ & 2 & 3 & 4 & $\begin{array}{l}5 \text { (most } \\
\text { deprived }\end{array}$ \\
\hline ST elevation myocardial infarctiont: & 110 & $1.9(0.6$ to 5.0$)$ & 19 & 21 & 21 & 23 & 24 \\
\hline $\begin{array}{l}\text { Community cardiopulmonary } \\
\text { resuscitation }\end{array}$ & 2 & 0.0 & 0 & 1 & 0 & 1 & 1 \\
\hline $\begin{array}{l}\text { Hospital cardiopulmonary } \\
\text { resuscitation } \neq\end{array}$ & 0 & 0.0 & 0 & 0 & 0 & 0 & 0 \\
\hline Thrombolysis $\ddagger$ & 0 & 0.0 & 0 & 0 & 0 & 0 & 0 \\
\hline Aspirin & 4 & 0.1 & 1 & 1 & 1 & 1 & 1 \\
\hline$\beta$ blockers & 0 & 0.0 & 0 & 0 & 0 & 0 & 0 \\
\hline ACE inhibitors/ARB & 0 & 0.0 & 0 & 0 & 0 & 0 & 0 \\
\hline $\begin{array}{l}\text { Primary percutaneous coronary } \\
\text { intervention }\end{array}$ & 90 & 1.6 & 16 & 18 & 18 & 19 & 19 \\
\hline Coronary artery bypass graft surgery & 0 & 0.0 & 0 & 0 & 0 & 0 & 0 \\
\hline Clopidogrel & 12 & 0.2 & 2 & 2 & 2 & 3 & 2 \\
\hline $\begin{array}{l}\text { Non-ST elevation acute coronary } \\
\text { syndromet: }\end{array}$ & 80 & $1.3(0.7$ to 2.4$)$ & 10 & 16 & 15 & 17 & 20 \\
\hline $\begin{array}{l}\text { Hospital cardiopulmonary } \\
\text { resuscitation } \neq\end{array}$ & 0 & 0.0 & 0 & 0 & 0 & 0 & 0 \\
\hline Aspirin and heparin & 40 & 0.7 & 8 & 11 & 40 & 5 & 8 \\
\hline Aspirin alone & 0 & 0.0 & 0 & 0 & 0 & 0 & 0 \\
\hline Platelet glycoprotein IIB/IIIA inhibitors & -0.1 & 0.0 & 0 & 0 & -0.1 & 0 & 0 \\
\hline Coronary artery bypass graft surgery & 0 & 0.0 & 0 & 0 & 0 & 0 & 0 \\
\hline Percutaneous coronary intervention & 7 & 0.1 & 1 & 2 & 7 & 1 & 2 \\
\hline ACE inhibitors/ARB & 5 & 0.1 & 1 & 1 & 5 & 1 & 1 \\
\hline$\beta$ blockers & 3 & 0.0 & 1 & 1 & 3 & 0 & 1 \\
\hline Clopidogrel & 23 & 0.4 & 5 & 5 & 23 & 4 & 5 \\
\hline $\begin{array}{l}\text { Secondary prevention post-myocardial } \\
\text { infarctiont: }\end{array}$ & 525 & 9.1 (7.4 to 11.2$)$ & 88 & 87 & 107 & 118 & 125 \\
\hline Aspirin & 35 & 0.6 & 7 & 4 & 9 & 7 & 9 \\
\hline$\beta$ blockers & 115 & 2.0 & 19 & 19 & 21 & 27 & 29 \\
\hline ACE inhibitors/ARB & 154 & 2.7 & 26 & 27 & 29 & 34 & 38 \\
\hline Statins & 169 & 2.9 & 27 & 29 & 36 & 38 & 38 \\
\hline Warfarin & 12 & 0.2 & 1 & 1 & 4 & 3 & 3 \\
\hline Rehabilitation & 39 & 0.7 & 6 & 7 & 8 & 9 & 8 \\
\hline $\begin{array}{l}\text { Secondary prevention } \\
\text { post-revascularisationt: }\end{array}$ & 120 & 2.1 (1.4 to 3.0$)$ & 20 & 20 & 27 & 26 & 26 \\
\hline Aspirin & -1 & 0.0 & 0 & -1 & 1 & -1 & 1 \\
\hline$\beta$ blockers & 29 & 0.5 & 4 & 4 & 6 & 8 & 7 \\
\hline ACE inhibitors/ARB & 46 & 0.8 & 8 & 7 & 11 & 10 & 9 \\
\hline Statins & 47 & 0.8 & 7 & 9 & 11 & 10 & 10 \\
\hline Warfarin & -4 & -0.1 & 0 & 0 & -2 & -2 & -1 \\
\hline $\begin{array}{l}\text { Rehabilitation (coronary artery bypass } \\
\text { graft)§ }\end{array}$ & 0.0 & 0.0 & 0.0 & 0.0 & 0.0 & 0.0 & 0.0 \\
\hline $\begin{array}{l}\text { Rehabilitation (percutaneous coronary } \\
\text { intervention) }\end{array}$ & 1.8 & 0.0 & 0.3 & 0.4 & 0.4 & 0.4 & 0.3 \\
\hline Chronic stable coronary artery disease: & 375 & 6.5 (4.6 to 9.1$)$ & 65 & 74 & 79 & 83 & 75 \\
\hline Coronary artery bypass graft surgery & -4 & -0.1 & -3 & 1 & 0 & 0 & -2 \\
\hline Aspirin & 43 & 0.8 & 8 & 9 & 8 & 9 & 10 \\
\hline Statins & 226 & 3.9 & 41 & 42 & 50 & 49 & 44 \\
\hline
\end{tabular}


Table 2 (continued)

\begin{tabular}{|c|c|c|c|c|c|c|c|}
\hline \multirow[b]{2}{*}{ Treatments by patient groups } & \multirow[b]{2}{*}{ All } & \multirow{2}{*}{$\begin{array}{l}\text { Proportion of total } \\
\text { DPPs-\% }(95 \% \\
\text { uncertainty } \\
\left.\text { interval }{ }^{*}\right)\end{array}$} & \multicolumn{5}{|c|}{ Scottish Index of Multiple Deprivation fifths } \\
\hline & & & $\begin{array}{c}1 \text { (most } \\
\text { affluent) }\end{array}$ & 2 & 3 & 4 & $\begin{array}{l}5 \text { (most } \\
\text { deprived }\end{array}$ \\
\hline ACE inhibitors & 111 & 1.9 & 19 & 23 & 21 & 25 & 23 \\
\hline Heart failure in hospitalt: & 85 & $1.5(1.0$ to 1.9$)$ & 12 & 13 & 18 & 19 & 23 \\
\hline ACE inhibitors & 22 & 0.4 & 3 & 4 & 5 & 5 & 5 \\
\hline$\beta$ blockers & 41 & 0.7 & 6 & 7 & 9 & 10 & 10 \\
\hline Spironolactone & 18 & 0.3 & 2 & 3 & 4 & 4 & 4 \\
\hline Aspirin & 4 & 0.1 & 1 & 0 & 1 & 0 & 3 \\
\hline Heart failure (community) $\dagger:$ & 265 & $4.6(3.6$ to 6.0$)$ & 29 & 39 & 58 & 65 & 76 \\
\hline ACE inhibitors & 35 & 0.6 & 3 & 5 & 10 & 7 & 10 \\
\hline$\beta$ blockers & 207 & 3.6 & 24 & 29 & 42 & 47 & 65 \\
\hline Spironolactone & 21 & 0.4 & 1 & 5 & 6 & 11 & -2 \\
\hline Aspirin & 4 & 0.1 & 1 & -1 & 0 & 0 & 3 \\
\hline Hypertension treatment $\dagger$ & 155 & $2.7(0.7$ to 6.0$)$ & 29 & 33 & 30 & 29 & 33 \\
\hline Hyperlipidaemia treatment (statins) $\dagger$ & 770 & $13.3(5.3$ to 30.4$)$ & 140 & 170 & 183 & 138 & 138 \\
\hline Total treatment $\dagger$ & 2480 & $43.0(33.0$ to 61.3$)$ & 412 & 473 & 538 & 517 & 540 \\
\hline
\end{tabular}

DPPs for Scotland (subtotals and total treatment only) have been rounded to nearest 5 (column 2).

$\mathrm{ACE}=$ angiotensin converting enzyme; $\mathrm{ARB}=$ angiotensin receptor blockers.

${ }^{*} 95 \%$ uncertainty interval corresponds to lower (2.5th centile) and upper (97.5th centile) limits of uncertainty analysis. These are shown to indicate range around central estimate of per cent of DPPs explained. Intervals are provided only for nine treatment patient groups.

†Subtotals (in rows) for coronary heart disease patient groups.

¥Assuming no change in thrombolysis and cardiopulmonary resuscitation uptake in community between 2000 and 2010; their contribution to DPPs have therefore been set to zero.

$\S$ No change in uptake between 2000 and 2010. 
Table 3/ Coronary heart disease deaths prevented or postponed (DPPs) as percentage of total DPPs to be explained, stratified by deprivation fifth; selected sex specific DPPs are provided

\begin{tabular}{|c|c|c|c|c|c|c|c|}
\hline \multirow[b]{2}{*}{$\begin{array}{l}\text { Treatments by patient groups/risk } \\
\text { factors }\end{array}$} & \multirow[b]{2}{*}{ Scotland } & \multicolumn{5}{|c|}{ Scottish Index of Multiple Deprivation fifths } & \multirow[b]{2}{*}{ P value ${ }^{*}$} \\
\hline & & 1 (most affluent) & 2 & 3 & 4 & $\begin{array}{c}5 \text { (most } \\
\text { deprived) }\end{array}$ & \\
\hline \multicolumn{8}{|l|}{ Treatments } \\
\hline ST elevation myocardial infarction & 1.9 & 2.1 & 2.0 & 1.5 & 1.9 & 2.0 & 0.96 \\
\hline $\begin{array}{l}\text { Non-ST elevation acute coronary } \\
\text { syndrome }\end{array}$ & 1.3 & 1.1 & 1.5 & 1.1 & 1.4 & 1.6 & 0.38 \\
\hline $\begin{array}{l}\text { Secondary prevention } \\
\text { post-myocardial infarction }\end{array}$ & 9.1 & 9.7 & 8.2 & 7.7 & 9.9 & 10.2 & 0.25 \\
\hline $\begin{array}{l}\text { Secondary prevention } \\
\text { post-revascularisation }\end{array}$ & 2.1 & 2.2 & 1.9 & 2.0 & 2.2 & 2.1 & 0.90 \\
\hline $\begin{array}{l}\text { Chronic stable coronary artery } \\
\text { disease }\end{array}$ & 6.5 & 7.2 & 7.0 & 5.7 & 7.0 & 6.1 & 0.40 \\
\hline Heart failure in hospital & 1.5 & 1.3 & 1.3 & 1.3 & 1.6 & 1.9 & 0.22 \\
\hline Heart failure in community & 4.6 & 3.2 & 3.7 & 4.2 & 5.5 & 6.2 & 0.0001 \\
\hline Hypertension treatment & 2.7 & 3.2 & 3.1 & 2.1 & 2.5 & 2.7 & 0.32 \\
\hline Hyperlipidaemia treatment (statins) & 13.3 & 15.4 & 16.1 & 13.1 & 11.7 & 11.2 & $<0.0001$ \\
\hline Total treatments-all $\dagger$ & 43.0 & 45.5 & 44.7 & 38.6 & 43.6 & 43.9 & 0.53 \\
\hline Total treatments-ment & 44.8 & 46.0 & 43.3 & 40.6 & 50.7 & 44.6 & 0.43 \\
\hline Total treatments-woment & 41.0 & 44.8 & 46.4 & 36.6 & 36.6 & 43.4 & 0.1 \\
\hline \multicolumn{8}{|l|}{ Risk factors } \\
\hline Smoking & 3.6 & 1.5 & 2.3 & 3.0 & 4.5 & 6.1 & $<0.0001$ \\
\hline Diabetes & -8.2 & -5.3 & -7.1 & -7.1 & -9.4 & -11.5 & $<0.0001$ \\
\hline Physical inactivity & 1.7 & 1.3 & 1.5 & 1.5 & 1.9 & 2.3 & 0.06 \\
\hline Systolic blood pressure, $\mathrm{mm} \mathrm{Hg}$ & 36.9 & 37.5 & 37.3 & 33.2 & 40.3 & 37.2 & 0.51 \\
\hline Total cholesterol, mmol/L & 8.9 & 4.7 & 5.4 & 6.8 & 12.3 & 13.8 & $<0.0001$ \\
\hline Body mass index & -4.1 & -3.9 & -4.1 & -3.6 & -4.5 & -4.3 & 0.49 \\
\hline Total risk factors $\dagger$ & 38.8 & 35.9 & 35.3 & 33.7 & 45.1 & 43.5 & $<0.0001$ \\
\hline Total risk factors-men† & 39.5 & 37.5 & 38.4 & 34.8 & 44.3 & 42.7 & 0.01 \\
\hline Total risk factors-women $†$ & 37.9 & 33.8 & 31.8 & 32.4 & 45.9 & 44.6 & $<0.0001$ \\
\hline \multicolumn{8}{|l|}{ Deaths prevented or postponed } \\
\hline DPPs explained by model一all $\dagger$ & 81.7 & 81.3 & 80.0 & 72.3 & 88.7 & 87.5 & $<0.0001$ \\
\hline DPPs explained by model-men $\dagger$ & 84.3 & 83.6 & 81.7 & 75.4 & 95.1 & 87.3 & $<0.0001$ \\
\hline DPPs explained by model-woment & 78.9 & 78.6 & 78.1 & 69.0 & 82.5 & 88.0 & $<0.0001$ \\
\hline DPPs not explained by model† & 18.3 & 18.7 & 20.0 & 27.7 & 11.3 & 12.5 & - \\
\hline \multicolumn{8}{|l|}{ DPP counts } \\
\hline DPPs explained by modeltł: & 4720 & 736 & 847 & 1006 & 1053 & 1075 & - \\
\hline Due to treatment uptakeł & 2480 & 412 & 473 & 538 & 517 & 540 & - \\
\hline Due to risk factor change $\ddagger$ & 2240 & 325 & 374 & 469 & 535 & 535 & - \\
\hline DPPs unexplained by modelt $\ddagger$ & 1055 & 169 & 212 & 385 & 134 & 154 & - \\
\hline Total DPPs†‡ & 5770 & 905 & 1060 & 1390 & 1185 & 1230 & - \\
\hline
\end{tabular}

${ }^{*} X^{2}$ test for linear trend.

†Subtotals (in rows).

¥Sex specific coronary heart disease DPPs as percentage of sex specific total DPPs to be explained (full sex stratified tables are available in technical appendix). $\ddagger D P P s$ for Scotland (column 2) and total DPPs (last row) have been rounded to nearest 5. 
Table 4| Coronary heart disease deaths prevented or postponed (DPPs) owing to changes in risk factor prevalence between 2000 and 2010 in Scotland stratified by deprivation fifth

\begin{tabular}{|c|c|c|c|c|c|c|c|}
\hline \multirow[b]{2}{*}{ Risk factors } & \multirow[b]{2}{*}{ Scotland } & \multirow{2}{*}{$\begin{array}{l}\text { Proportion of total DPPs_\% } \\
\left(95 \% \text { uncertainty interval }{ }^{\star}\right)\end{array}$} & \multicolumn{5}{|c|}{ Scottish Index of Multiple Deprivation fifths } \\
\hline & & & 1 (most affluent) & 2 & 3 & 4 & 5 (most deprived) \\
\hline Smoking & 210 & $3.6(2.5$ to 5.0$)$ & 14 & 25 & 41 & 53 & 75 \\
\hline Diabetes & -475 & $-8.2(-11.1$ to -5.9$)$ & -48 & -75 & -99 & -112 & -141 \\
\hline Physical inactivity & 100 & $1.7(1.5$ to 2.4$)$ & 12 & 16 & 21 & 23 & 28 \\
\hline $\begin{array}{l}\text { Systolic blood pressure, mm } \\
\mathrm{Hg} \dagger\end{array}$ & 2130 & 36.9 (27.4 to 44.5$)$ & 340 & 394 & 461 & 479 & 457 \\
\hline Total cholesterol, $\mathrm{mmol} / \mathrm{L} \ddagger$ & 510 & $8.9(4.0$ to 13.7$)$ & 43 & 57 & 95 & 147 & 170 \\
\hline Body mass index & -235 & $-4.1(-5.6$ to -2.4$)$ & -35 & -44 & -50 & -54 & -53 \\
\hline Total risk factors & 2240 & 38.8 (27.9 to 49.0$)$ & 325 & 374 & 469 & 535 & 535 \\
\hline Total treatment§ & 2480 & 43.0 (33.0 to 61.3 ) & 412 & 473 & 538 & 517 & 540 \\
\hline DPPs explained by model & 4720 & 81.7 (64.7 to 98.8 ) & 736 & 847 & 1006 & 1053 & 1075 \\
\hline DPPS not explained & 1055 & - & 169 & 212 & 385 & 134 & 154 \\
\hline Total DPPs & 5770 & - & 905 & 1060 & 1390 & 1185 & 1230 \\
\hline
\end{tabular}

DPPs for Scotland (column 2) and total DPPs (last row) have been rounded to nearest 5.

${ }^{*} 95 \%$ uncertainty interval corresponds to lower (2.5th centile) and upper (97.5th centile) limits of uncertainty analysis.

†After subtracting DPPs due to hypertension treatment in primary prevention.

$\ddagger$ After subtracting DPPs due to statin treatment in primary prevention.

$\S$ See table 2 for detailed breakdown by patient group and treatment type. 


\begin{tabular}{|c|c|c|c|c|c|c|c|c|c|c|c|c|}
\hline \multirow[b]{3}{*}{ Treatment by patient group } & & & \multicolumn{10}{|c|}{ Scottish Index of Multiple Deprivation fifths } \\
\hline & \multicolumn{2}{|c|}{ Scotland } & \multicolumn{2}{|c|}{1} & \multicolumn{2}{|c|}{2} & \multicolumn{2}{|c|}{3} & \multicolumn{2}{|c|}{4} & \multicolumn{2}{|c|}{5} \\
\hline & 2000 & 2010 & 2000 & 2010 & 2000 & 2010 & 2000 & 2010 & 2000 & 2010 & 2000 & 2010 \\
\hline \multicolumn{13}{|l|}{$\begin{array}{l}\text { ST elevation myocardial infarction } \\
\left(2500^{\star}\right) \text { : }\end{array}$} \\
\hline Thrombolysis & 77.6 & 58.5 & 79.7 & 60.5 & 78.0 & 62.1 & 75.9 & 59.4 & 76.3 & 57.4 & 78.7 & 54.5 \\
\hline Aspirin & 93.6 & 96.6 & 93.7 & 97.0 & 94.6 & 96.9 & 93.0 & 96.1 & 93.1 & 96.4 & 93.8 & 96.8 \\
\hline$\beta$ blocker & 71.7 & 72.8 & 75.2 & 72.9 & 72.6 & 71.9 & 71.4 & 72.0 & 69.7 & 72.1 & 71.4 & 74.7 \\
\hline $\begin{array}{l}\text { ACE inhibitor or angiotensin } \\
\text { receptor blocker }\end{array}$ & 77.5 & 78.3 & 79.8 & 78.4 & 79.0 & 77.4 & 75.9 & 77.5 & 75.5 & 77.0 & 78.5 & 80.9 \\
\hline Clopidogrel & 28.1 & 90.0 & 27.1 & 90.2 & 25.8 & 89.3 & 28.0 & 90.3 & 29.1 & 89.9 & 29.2 & 90.4 \\
\hline $\begin{array}{l}\text { Primary percutaneous coronary } \\
\text { intervention }\end{array}$ & 4.2 & 58.6 & 6.2 & 66.7 & 4.0 & 58.4 & 4.1 & 55.8 & 5.0 & 56.2 & 2.6 & 58.4 \\
\hline $\begin{array}{l}\text { Primary coronary artery bypass } \\
\text { graft }\end{array}$ & 0.0 & 0.1 & 0.0 & 0.3 & 0.2 & 0.0 & 0.0 & 0.0 & 0.0 & 0.2 & 0.0 & 0.0 \\
\hline CPR in hospital & 11.2 & 5.8 & 9.8 & 5.8 & 11.4 & 6.1 & 11.7 & 5.5 & 11.7 & 5.9 & 11.1 & 5.6 \\
\hline CPR in community $\left(1315^{\star}\right)$ & 23.4 & 28.3 & 26.6 & 27.8 & 24.2 & 32.4 & 25.8 & 25.3 & 21.1 & 26.4 & 21.5 & 29.5 \\
\hline \multicolumn{13}{|l|}{$\begin{array}{l}\text { Non-ST elevation acute coronary } \\
\text { syndrome }\left(9110^{*}\right) \text { : }\end{array}$} \\
\hline Aspirin and heparin & 64.0 & 79.9 & 67.4 & 79.7 & 65.6 & 80.7 & 67.0 & 80.1 & 65.9 & 80.1 & 58.0 & 78.9 \\
\hline Aspirin alone & 24.3 & 12.8 & 21.4 & 13.6 & 23.5 & 12.2 & 21.4 & 12.6 & 23.4 & 12.5 & 28.8 & 13.1 \\
\hline $\begin{array}{l}\text { Platelet glycoprotein IIB/IIIA } \\
\text { inhibitors }\end{array}$ & 6.0 & 5.9 & 9.6 & 6.3 & 7.4 & 6.0 & 6.3 & 5.3 & 4.8 & 5.1 & 4.6 & 7.0 \\
\hline $\begin{array}{l}\text { ACE inhibitor or angiotensin } \\
\text { receptor blocker }\end{array}$ & 66.2 & 73.5 & 68.8 & 73.3 & 64.3 & 72.6 & 66.2 & 72.8 & 64.5 & 72.8 & 67.7 & 75.2 \\
\hline$\beta$ blocker & 63.9 & 67.9 & 66.9 & 68.3 & 63.5 & 68.3 & 64.2 & 67.1 & 62.5 & 66.2 & 63.9 & 69.5 \\
\hline Clopidogrel & 45.1 & 86.8 & 44.0 & 87.3 & 44.7 & 87.4 & 43.0 & 87.1 & 46.2 & 86.0 & 46.4 & 86.5 \\
\hline $\begin{array}{l}\text { Coronary artery bypass graft } \\
\text { surgery }\end{array}$ & 0.4 & 0.4 & 0.9 & 0.3 & 0.4 & 0.6 & 0.3 & 0.5 & 0.4 & 0.3 & 0.4 & 0.2 \\
\hline $\begin{array}{l}\text { Percutaneous coronary } \\
\text { intervention }\end{array}$ & 3.5 & 6.7 & 5.6 & 7.9 & 3.1 & 7.8 & 4.2 & 6.2 & 3.3 & 5.9 & 2.6 & 6.4 \\
\hline \multicolumn{13}{|l|}{ CPR in community } \\
\hline CPR in hospital $\left(4640^{*}\right)$ & 5.2 & 2.4 & 4.5 & 2.3 & 4.8 & 2.2 & 5.3 & 2.2 & 5.5 & 2.7 & 5.5 & 2.4 \\
\hline \multicolumn{13}{|l|}{$\begin{array}{l}\text { Secondary prevention } \\
\text { post-myocardial infarction }(60 \\
\left.200^{*}\right) \text { : }\end{array}$} \\
\hline Aspirin & 68.6 & 80.5 & 67.4 & 80.0 & 69.1 & 78.8 & 67.3 & 78.8 & 69.3 & 80.9 & 69.2 & 83.3 \\
\hline$\beta$ blocker & 45.7 & 65.8 & 50.9 & 67.5 & 45.5 & 63.3 & 47.5 & 64.2 & 44.0 & 65.3 & 43.1 & 68.6 \\
\hline ACE inhibitor & 26.5 & 68.0 & 26.4 & 68.3 & 29.2 & 67.1 & 26.6 & 64.5 & 26.7 & 69.2 & 24.6 & 70.2 \\
\hline Statin & 41.7 & 86.6 & 43.4 & 84.9 & 44.2 & 84.6 & 40.9 & 85.7 & 41.6 & 87.0 & 39.8 & 89.5 \\
\hline Warfarin & 4.7 & 6.0 & 5.3 & 6.5 & 5.9 & 6.0 & 4.9 & 6.9 & 4.2 & 5.3 & 4.0 & 5.7 \\
\hline Rehabilitation & 17.1 & 42.1 & 17.0 & 41.7 & 17.0 & 41.9 & 17.0 & 42.1 & 17.1 & 42.0 & 17.3 & 42.8 \\
\hline
\end{tabular}

Secondary prevention

post-revascularisation (40 295):

\begin{tabular}{lcccccccccccc}
\hline Aspirin & 75.6 & 79.2 & 72.5 & 75.1 & 81.4 & 80.6 & 70.3 & 78.5 & 77.1 & 78.0 & 76.8 & 83.8 \\
\hline B blocker & 45.3 & 62.0 & 48.5 & 60.3 & 48.4 & 61.8 & 47.1 & 62.4 & 39.1 & 59.7 & 44.9 & 65.9 \\
\hline ACE inhibitor & 20.7 & 59.5 & 21.8 & 56.9 & 22.0 & 53.9 & 16.3 & 60.3 & 24.1 & 65.3 & 19.4 & 60.2 \\
\hline Statin & 62.4 & 90.9 & 67.3 & 89.5 & 62.6 & 88.5 & 57.4 & 90.3 & 63.8 & 92.3 & 61.2 & 93.4 \\
\hline Warfarin & 8.5 & 7.3 & 6.0 & 8.3 & 6.8 & 7.6 & 11.2 & 8.1 & 9.8 & 7.7 & 8.1 & 5.0 \\
\hline Rehabilitation (CABG) $\left(7115^{*}\right)$ & 42.5 & 41.9 & 43.1 & 41.9 & 42.6 & 42.4 & 42.6 & 41.7 & 42.5 & 42.0 & 42.0 & 41.3 \\
\hline Rehabilitation (PCI) $\left(11100^{*}\right)$ & 7.5 & 12.4 & 7.5 & 12.6 & 7.5 & 12.4 & 7.5 & 12.3 & 7.5 & 12.4 & 7.5 & 12.2 \\
\hline
\end{tabular}

Chronic stable coronary artery disease $\left(72395^{\star}\right)$ :

Aspirin in community $\begin{array}{llll}59.6 & 73.6 & 57.7 & 71.4\end{array}$ $60.3 \quad 72.0$ $57.4 \quad 72.2$ $61.2 \quad 75.0$ $60.7 \quad 77.2$ 
Table 5 (continued)

\begin{tabular}{|c|c|c|c|c|c|c|c|c|c|c|c|c|}
\hline \multirow[b]{3}{*}{ Treatment by patient group } & & & \multicolumn{10}{|c|}{ Scottish Index of Multiple Deprivation fifths } \\
\hline & \multicolumn{2}{|c|}{ Scotland } & \multicolumn{2}{|c|}{1} & \multicolumn{2}{|c|}{2} & \multicolumn{2}{|c|}{3} & \multicolumn{2}{|c|}{4} & \multicolumn{2}{|c|}{5} \\
\hline & 2000 & 2010 & 2000 & 2010 & 2000 & 2010 & 2000 & 2010 & 2000 & 2010 & 2000 & 2010 \\
\hline Statins in community & 28.7 & 78.6 & 31.1 & 77.6 & 27.6 & 76.3 & 30.2 & 78.4 & 28.9 & 81.7 & 26.8 & 78.4 \\
\hline ACE inhibitor & 15.3 & 45.2 & 16.8 & 45.2 & 15.7 & 45.1 & 14.6 & 41.7 & 15.7 & 47.9 & 14.8 & 46.4 \\
\hline CABG surgery (previous 5 years) & 11.8 & 9.8 & 16.0 & 11.9 & 11.9 & 10.5 & 10.2 & 8.6 & 11.4 & 9.9 & 11.4 & 8.8 \\
\hline \multicolumn{13}{|l|}{ Heart failure in hospital $\left(3645^{\star}\right)$} \\
\hline ACE inhibitor & 51.4 & 64.3 & 50.1 & 62.6 & 50.1 & 62.7 & 51.5 & 64.4 & 51.8 & 64.7 & 52.7 & 65.8 \\
\hline$\beta$ blocker & 31.9 & 45.6 & 31.0 & 44.2 & 31.1 & 44.4 & 32.0 & 45.7 & 32.2 & 46.0 & 32.7 & 46.7 \\
\hline Spironolactone & 21.0 & 26.2 & 20.5 & 25.6 & 20.3 & 25.4 & 21.1 & 26.4 & 21.2 & 26.6 & 21.2 & 26.5 \\
\hline Aspirin & 71.9 & 79.9 & 70.8 & 80.7 & 74.9 & 77.1 & 68.6 & 78.8 & 72.7 & 80.1 & 72.4 & 82.3 \\
\hline \multicolumn{13}{|l|}{$\begin{array}{l}\text { Heart failure in community (16 } \\
225) \text { : }\end{array}$} \\
\hline $\begin{array}{l}\text { ACE inhibitor/or angiotensin } \\
\text { receptor blocker }\end{array}$ & 69.7 & 81.4 & 72.6 & 79.7 & 72.5 & 79.4 & 61.5 & 79.3 & 70.0 & 79.7 & 72.7 & 86.5 \\
\hline$\beta$ blocker & 30.9 & 65.8 & 34.3 & 57.3 & 28.2 & 60.0 & 32.8 & 66.9 & 28.2 & 65.5 & 32.1 & 73.3 \\
\hline Spironolactone & 7.7 & 11.7 & 6.2 & 7.8 & 10.4 & 14.5 & 6.6 & 12.7 & 6.5 & 16.4 & 8.2 & 7.4 \\
\hline Aspirin & 74.3 & 75.1 & 71.9 & 75.4 & 71.8 & 76.9 & 71.2 & 71.6 & 77.8 & 73.7 & 77.0 & 77.7 \\
\hline $\begin{array}{l}\text { Hypertension treatment ( } 3685 \\
\left.545^{\star}\right)\end{array}$ & 12.2 & 18.3 & 9.4 & 15.6 & 12.4 & 19.3 & 12.2 & 17.8 & 12.9 & 18.8 & 14.0 & 19.9 \\
\hline $\begin{array}{l}\text { Hyperlipidaemia treatment (statins) } \\
\left(3685545^{\star}\right)\end{array}$ & 2.7 & 15.1 & 2.2 & 13.2 & 2.8 & 15.8 & 2.8 & 15.3 & 2.6 & 14.3 & 3.2 & 17.0 \\
\hline
\end{tabular}

Overall treatment uptake rate is weighted average over all age groups $\geq 25$ years and both sexes.

$\mathrm{ACE}=$ angiotensin converting enzyme; $\mathrm{CABG}=$ coronary artery bypass graft; $\mathrm{CPR}=$ cardiopulmonary resuscitation; $\mathrm{PCl}=$ percutaneous coronary intervention.

*Number of eligible patients, rounded to nearest 5. 
Table 6 | Absolute change in risk factor levels between 2000 and 2010, stratified by deprivation fifths

\begin{tabular}{|c|c|c|c|c|c|c|c|c|}
\hline \multirow[b]{3}{*}{ Risk factor } & \multirow{2}{*}{\multicolumn{2}{|c|}{ Overall levels* $^{*}$}} & \multicolumn{6}{|c|}{ Change in risk factors } \\
\hline & & & \multirow[b]{2}{*}{ Scotland } & \multicolumn{5}{|c|}{ Scottish Index of Multiple Deprivation fifths } \\
\hline & 2000 & 2010 & & 1 (most affluent) & 2 & 3 & 4 & 5 (most deprived) \\
\hline \multicolumn{9}{|c|}{ Smoking prevalence (\%): } \\
\hline Men & 30.3 & 26.0 & -4.3 & -2.8 & -3.5 & -4.3 & -4.9 & -5.5 \\
\hline Women & 28.9 & 23.7 & -5.2 & -3.2 & -4.0 & -5.1 & -5.9 & -7.0 \\
\hline \multicolumn{9}{|c|}{ Diabetes prevalence (\%): } \\
\hline Men & 4.2 & 7.3 & 3.1 & 2.2 & 3.0 & 3.3 & 3.3 & 3.5 \\
\hline Women & 3.4 & 5.3 & 1.9 & 1.2 & 1.3 & 2.1 & 2.1 & 2.6 \\
\hline \multicolumn{9}{|c|}{ Physical inactivity (\%): } \\
\hline Men & 66.3 & 58.9 & -7.4 & -7.5 & -7.3 & -7.1 & -7.3 & -7.8 \\
\hline Women & 74.6 & 68.4 & -6.2 & -6.0 & -6.2 & -6.1 & -6.2 & -6.5 \\
\hline \multicolumn{9}{|c|}{ Systolic blood pressure, mm Hg: } \\
\hline Men & 133.1 & 132.2 & -0.9 & -1.0 & -1.0 & -1.0 & -0.9 & -0.8 \\
\hline Women & 130.1 & 126.9 & -3.2 & -3.1 & -3.1 & -3.1 & -3.3 & -3.2 \\
\hline \multicolumn{9}{|c|}{ Total cholesterol, mmol/L: } \\
\hline Men & 5.6 & 5.2 & -0.4 & -0.4 & -0.4 & -0.4 & -0.4 & -0.4 \\
\hline Women & 5.7 & 5.4 & -0.3 & -0.3 & -0.3 & -0.3 & -0.3 & -0.3 \\
\hline \multicolumn{9}{|c|}{ Body mass index, $\mathrm{kg} / \mathrm{m}^{2}$ : } \\
\hline Men & 27.3 & 28.2 & 0.9 & 0.9 & 0.9 & 0.9 & 0.9 & 0.9 \\
\hline Women & 27.1 & 27.9 & 0.8 & 0.8 & 0.8 & 0.8 & 0.9 & 0.8 \\
\hline
\end{tabular}

${ }^{*}$ Scotland average weighted by 2010 population distribution in 10 year age bands. 